Published in final edited form as:

Clin Plast Surg. 2017 July ; 44(3): 535-540. doi:10.1016/j.cps.2017.02.026.

\title{
Sedation and Pain Management in Burn Patients
}

\author{
Cornelia Griggs, Jeremy Goverman, Edward Bittner, and Benjamin Levi
}

\author{
Keywords \\ Pain Management; Sedation; Burn; Anesthesia; Operative Management
}

\section{INTRODUCTION}

From the moment of injury through rehabilitation and beyond, pain control is a major challenge in the management of patients with burn injuries. In fact, some argue that burn pain is the most difficult to treat among any etiology of acute pain (DR Patterson 2004). The therapies used to treat burn injuries may exacerbate the difficulty of pain control because most of these interventions are associated with pain - be it dressing changes, excision and grafting, or physical therapy. These therapies can cause pain that is equivalent to or worse than the pain of an initial burn injury. Therefore, pain management must be a foundation of burn care. Good pain control is linked to better wound healing, sleep, participation in activities of daily living, quality of life and recovery (Raymond 2004, Christian 2006).

Despite profound improvements in modern burn care, suboptimal and inconsistent pain management persists throughout all stages of burn treatment. Without aggressive pain control, patients are likely to suffer not only from the acute experience of pain in itself, but the secondary morbidities of higher pain levels, including long-term anxiety and posttraumatic stress (DR Patterson 1990, Saxe GN 2005) or even delayed wound healing (Brown 2014). The unique challenge of burn pain is further complicated by a relative dearth of standardized approaches (Faucher 2006). Instead, tradition and personal/institutional biases often dictate pain management. The complex interaction of anatomic, physiologic, pharmacologic, psychosocial, and premorbid issues can make the treatment of burn pain particularly difficult. An overview of pain management strategies specific to the treatment of burn injuries is summarized here.

\section{MECHANISMS AND TYPES OF PAIN IN BURNS}

While burns are classified according to depth, area and severity of injury, pain does not necessarily correlate with these measures. The individual experience of pain varies widely between patients and throughout the healing process in burn injuries (Faucher 2006).

CONTACT: Benjamin Levi, MD, Assistant Professor, Division of Plastic Surgery, University of Michigan, 1500 East Medical Center Drive, Ann Arbor, MI 48109, blevi@med.umich.edu.

Publisher's Disclaimer: This is a PDF file of an unedited manuscript that has been accepted for publication. As a service to our customers we are providing this early version of the manuscript. The manuscript will undergo copyediting, typesetting, and review of the resulting proof before it is published in its final citable form. Please note that during the production process errors may be discovered which could affect the content, and all legal disclaimers that apply to the journal pertain. 
Because individuals have varying pain thresholds, coping abilities and even physiologic responses to injury, patients may experience disparate levels of pain despite having similar injuries (Faucher 2006). The most immediate and acute form of burn pain is the inflammatory nociceptive pain attributed to burn injury and tissue trauma. Nociceptive pain is often followed by and potentially exacerbated by procedural pain related to the treatment of burn wounds, be it surgical debridement, grafting, staple application and removal, physical therapy, or dressing changes. As burn wounds begin to heal, neuropathic pain characterized by a throbbing or constant burning sensation potentially adds an additional layer of discomfort.

While all burns are painful, conventionally, deeper, full thickness burns are thought to be somewhat less painful than superficial and partial thickness burns because of afferent nerve destruction (Meyer WJ, 2012). However, this does not always play out in clinical practice (Choiniere M, 1989). Additionally, full thickness burns eventually require debridement and grafting and subsequent dressing changes which all lead to substantial pain. At the time of burn injury, tissue damage is the primary mechanism of pain. Stimulation of local nociceptors transmits an impulse via Ad and C fibers to the dorsal horn of the spinal cord. Peripheral sensory nerves and descending influences from cortical areas can modulate the magnitude of the pain impulse (Richardson 2009). Ultimately, conscious perception of pain is regulated by areas of the brain often named the "pain matrix" which is thought to involve a network of higher cortical areas and the thalamus (Tracey 2008). The conscious perception of pain is affected not only by the burn wound itself but also by context, cognition, pharmacologics, mood and other predisposing factors (Richardson 2009). Burn pain may also vary and fluctuate widely over the span of recovery. Therefore, the successful treatment of burn pain should involve a multi-modal approach tailored to the patient and scenario.

\section{PAIN ASSESSMENT}

The first step in determining a pain treatment plan is assessing the degree of the patient's pain, which, in the case of burn injuries, may be mild to excruciating. Reliable, valid pain assessment tools in form of verbal adjective, numeric, or visual analog scales can be useful guides for pain management in burns. In adults, visual analog and numeric rating scales are commonly used (Wibbenmeyer 2011). Both NRS and VAS have undergone repeated validation and have performed well in different patient populations (Williamson 2005). Children, especially those who are preverbal, and well as non-communicative adults present a more difficult challenge. Observational scales and physiologic indicators such as heart rate and blood pressure may be used to gauge pain in these populations.

Second, understanding the type and chronicity of patient's pain is useful for tailoring pain management strategies. Patterson's burn pain paradigm provides a roadmap for the management of burn pain through five different phases of injury, treatment and recovery (Bonica's 2010). (1) Background pain is pain that is present while the patient is at rest, results from the thermal tissue injury itself, and is typically of low to moderate intensity and long duration. (2) Procedural pain is brief but intense pain that is generated by wound debridement and dressing changes and/or rehabilitation activities. (3) Breakthrough pain describes unexpected spikes of pain that occur when background analgesic effects are 
exceeded, either at rest, during procedures, or with stress. (4) Procedural pain is an expected and temporary increase in pain that occurs after burn excision, donor skin harvesting, grafting, or interventions such as the placement of central lines due to the creation of new and painful wounds in the process. (5) Chronic pain is pain that lasts longer than six months or remains after all burn wounds and skin graft donor sites have healed. The most common form of chronic pain is neuropathic pain, which is the result of damage sustained by the nerve endings in the skin. Each of these five phases presents unique challenges in the management of burn pain. Clinicians should be prepared to adjust treatment strategies using both pharmacologic and nonpharmacologic techniques, discussed in further detail below.

\section{PATHOPHYSIOLOGY AND PHARMACOLOGIC CONSIDERATIONS}

Major burns cause massive tissue destruction and activation of a cytokine-mediated inflammatory response leading to dramatic pathophysiologic effects (Bittner 2016). The inflammatory response is initiated within minutes of burn injury, which results in a cascade of irritants that sensitize and stimulate pain fibers. Burn wounds may become primarily hyperalgesic to mechanical and/or thermal stimuli (Richardson 2009). Two distinct phases, a burn shock phase followed by a hypermetabolic phase, were first described by Cuthbertson in 1942. (Cuthbertson 1942). Burns involving more than $20 \%$ of total body surface area (TBSA) cause generalized edema even in non-injured tissues (Bittner 2016). Continued loss of plasma into burned tissue can occur up to the first 48 hours or even longer in these larger burns (Bittner 2016). These profound physiologic changes contribute to altered pharmacokinetic and pharmacodynamic responses to many drugs (Bittner 2016). Plasma protein loss through burned skin and further dilution of plasma proteins by resuscitation fluids decrease the concentration of albumin (Bittner 2016). Increase in volume of distribution has been shown in almost every drug studied including propofol, fentanyl, and muscle relaxants (Blancet 2008). Burned patients may demonstrate variable or unpredictable responses to drugs, thereby requiring adjustments to dosing or complete exclusion of certain drugs (e.g., succinylcholine) (Bittner 2016). Cardiac output goes down in the acute injury phase $(0-48 \mathrm{~h})$ even with aggressive volume resuscitation. As a result, elimination of some drugs by the kidney and liver may be decreased. Next, the hyperdynamic phase leads to increased cardiac output and blood flow to the kidneys and liver, meaning increased clearance of drugs dependent on organ blood flow for elimination (Bittner 2016).

\section{PHARMACOLOGIC MANAGEMENT}

Oral NSAIDs and acetaminophen are mild analgesics that exhibit a ceiling effect in their dose-response relationship. Such limitations render these agents unsuitable for the treatment of typical, severe burn pain. Oral NSAIDS and acetaminophen are of benefit in treating minor burns, usually in the outpatient setting. For hospitalized burn patients, opioids are the cornerstone of pharmacologic pain control (Patterson 2004). Opiods are inexpensive, widely available, and familiar to the majority of clinicians. Opioid requirements are increased in burn patients and may far exceed standard dosing recommendations; therefore, tolerance is a challenge throughout burn care (Bittner 2016). Patient-controlled analgesia (PCA) with IV opioids is a safe and efficient method of achieving flexible analgesia in burn injured patients (Patterson 2004). Studies comparing PCA with other routes of administration have shown 
mixed results as to benefit and patient satisfaction (Faucher 2006). While opioids delivered via oral and intravenous routes are a mainstay of burn pain treatment, it is important to note that pharmacokinetic changes have been documented for morphine, fentanyl and propofol throughout the hyperdynamic and hypermetabolic stages of burn recovery (Han 2009). Animal studies of burn injury have shown changes in spinal cord receptors including down regulation of opioid receptors, and upregulation of PKC- $\gamma$ and N-methyl-D-aspartate (NMDA) receptors (Wang 2011). Therefore, ketamine requirements to anesthetize patients burn patients may also be increased (Bittner, 2016). For burn patients who develop extreme tolerance to morphine, clonidine, dexmedetomidine, ketamine and methadone have been found to be effective in the treatment of pain (Kariya 1998 Williams 1998).

Dexmedetomidine has been used to provide sedation-analgesia for burned patients and to decrease opioid requirements (Walker 2006, Lin 2001). Titration of dexmedetomidine may also allow weaning of benzodiazepine as patients get close to extubation. Dexmedetomidine has been shown to result in less delirium than benzodiazepines in several critical care studies.

Ketamine has many potential advantages for induction and maintenance of anesthesia in burn patients (Bittner 2006). Ketamine is associated with hemodynamic stability, preserving airway patency as well as hypoxic and hypercapnic responses, and decreasing airway resistance; therefore, ketamine may be the agent of choice particularly in scenarios where airway manipulation is to be avoided (Bittner 2006). Intensive dressing changes at the bedside, removal of hundreds of staples, or other procedures requiring conscious sedation are examples where ketamine might be the agent of choice. Administration of benzodiazepines along with ketamine can reduce dysphoria and co-administered glycopyrrolate can reduce the severity of increased secretions associated with ketamine. Burned patients receiving ketamine must be closely monitored for myocardial depressant affects however, because persistently high levels of catecholamines results in desensitization and down regulation of $\beta$-adrenoreceptors in these patients (Bittner 2006). Additionally, patients with prior drug use might experience distressing anxiety with ketamine use.

Anxiety is a common issue for burn injured patients and may be closely linked to pain for burn injured patients. Background pain and the anticipation of procedural pain exacerbates anxiety, which can in turn exacerbate the pain (Faucher 2006). Anxiolytic drugs have commonly been used in conjunction with opioids in the treatment of burn pain (Patterson 2004). When administered as an adjunct to opioids, benzodiazepines have been shown to decrease both background pain and pain in those patients with high levels of procedural pain (Patterson 2004). Futhermore, low dose benzodiazepine administration may reduce burn wound care pain reports (Patterson 2004). Patients with high anticipatory procedural anxiety and high levels of pain are most likely to benefit from anxiolytic therapy (Faucher 2006).

However, benzodiazepine use, as in other critical care populations can lead to short term and long term delirium. Antipsychotic medications (e.g. haloperidol and quetiapine) are also good options and are increasingly utilized for management of anxiety and agitation associated with burns. Antidepressants appear to enhance opiate-induced analgesia, especially in patients with chronic (neuropathic) pain (Bittner 2016). 


\section{INTRAOPERATIVE MANAGEMENT \& REGIONAL ANESTHESIA}

In addition to anesthetic concerns, intraoperative management of burned patients may demand special attention to airway access, vascular access, monitoring and ventilator management, all of which may be affected by the severity and location of a patient's burn. Facial burns, increased risk of infection from vascular access, profound fluids shifts and dynamic pharmacokinetic changes during the acute injury phase make intraoperative mangement of burned patients particularly challenging. If muscle relaxants are given intraoperatively, succinylcholine should not be administered within the first 48 hours of injury due to the risk of exaggerated hyperkalemic response in burned patients (Martyn 2006). Decreased sensitivity to the neuromuscular effects of nondepolarizing muscle relaxants (NDMRs) has also been observed in this population; therefore the dosage of NDMRs needed to achieve desired paralysis may be substantially increased in burned patients (Bittner 2016). Rocuronium and atracuronium also demonstrate somewhat reduced effectiveness in burned patients and may require increased dosing as well (Bittner 2016). Choice of anesthetic should be determined by the hemodynamics, pulmonary status and predicted difficulty of securing an airway. The choice of volatile anesthetic is not thought to change outcome in burned patients. However, if propofol is chosen as the agent for induction or sedation then the operative team must pay mind to the fact that clearance and volume of distribution may be markedly increased (Bittner 2016). Therefore, patients with major burn injuries may require larger bolus doses and/or increased infusion rates of propofol intraoperatively (Bittner 2016).

Regional anethesia has an important role in the intraoperative management of burn patients not only because it provides anesthesia in the operating room, but also because it can offer postoperative pain control and facilitates rehabilitation. Regional anesthesia should be considered both for burn wound pain as well as donor site pain. If both burn and donor sites are on the same extremity, regional anesthesia can be considered. Lateral femoral cutaneous nerve blocks can also be used to improve thigh donor site pain.

Tumescent local anesthesia injected into a donor site prior to harvesting, subcutaneous catheter infusions, peripheral nerve and central neuraxial blocks may all have roles in the regional management of burn pain. The use of epidural analgesia has been limited in the burn population because of the potential for increased risk of infection and colonization that has been associated with indwelling vascular access. Therefore, caution should be exercised in selecting appropriate burn patients that might benefit from central neuroaxial blockade (Bittner 2016). Truncal blocks can be very advantageous for donor site harvesting. The lateral femoral cutaneous nerve block is particularly well suited for this approach because it is exclusively a sensory nerve and innervates the lateral thigh, which is a donor site for splitthickness skin grafts (Bittner 2016).

\section{STRATEGIES FOR WEANING VENTILATOR}

Weaning the ventilator while maintaining appropriate pain control is one of the most challenging aspects of burn care. Historically burn patients would remain intubated and sedated for weeks to months during their burn care negating the need to titrate pain medications. With obvious improved outcomes with the push for daily spontaneous 
breathing trials, early extubation and ambulation in multiple surgical critical care populations, burn patients have also benefited from more rapid extubation. Concurrently, transitioning burn patients off of the high doses of pain medications need for analgesia can be challenging. In general, patients who are expected to be extubated within the first 48 hours of admission might tolerate propofol. However, as mentioned above, propofol can cause hypotension and high doses may be required given the high fluid resuscitation in burn patients. Additionally, triglycerides must be monitored for high doses. If patients are expected to be on the ventilator for greater than 48 hours as is seen in inhalation injuries, fentanyl and versed is often titrated. As mentioned above, dexmetatomidine can be added to help wean versed as the patient gets closer to extubation. Seroquel also serves as a helpful adjunct when beginning to wean benzodiazepine.

\section{CHRONIC PAIN MANAGEMENT}

Sensitivity to analgesics can fluctuate over the course of burn injury and recovery, with periods of increased sensitivity acutely followed by tolerance in the long term. Opioidinduced hyperalgesia is a complication that may result from the continuous administration of analgesics, therefore creating a cycle of increased opioid dosing and tolerance. Methadone is a synthetic opioid drug that has both a long and predictable duration of action, making this drug a favorable drug for chronic pain management in the burn patient population. Because methadone exerts its analgesic effect not only through opiate receptor binding but also through a weaker pain modulation at spinal NMDA receptors, it can be a strategic drug choice when making an opioid switch in burn patients (Richardson 2009). Neuropathic pain is also an important consideration in both healed and unhealed burn wounds. Gabapentin is an agent that has been studied in both the acute and chronic management of burn pain. The use of gabapentin as an adjunct to standard analgesia has shown reduction in the severity neuropathic pain in limited studies of burn patients and burn injury models (Gray 2008, Dirks 2002). However, recent data from a randomized, double-blind, placebo-controlled study showed that the use of gabapentin in acute burn pain management did not decrease pain scores or lessen opioid requirements (Wibbenmeyer 2014). Antidepressants and clonidine have also been proposed as potential analgesic options for chronic burn pain but have not been studied extensively. Further research into long-term opioid management and non-opioid adjuncts for chronic burn pain analgesia is needed.

\section{NON PHARMACOLOGIC APPROACHES}

Hypnosis, cognitive behavioral techniques, and distraction approaches are examples of nonpharmocologic strategies that have been studied in burn populations. The use of hyponosis for the treatment of procedural pain and anxiety and has growing evidence for its effectiveness (Lynn 2007). Virtual reality systems have also been studied and shown some promise in procedural pain control, but may not be practical in certain clinical settings (Hoffman 2000, Hoffman 2008). Multidisciplinary interventions from psychologists, physiotherapists and pain management specialists can contribute greatly to the burn patient's recovery. Early introduction to these support mechanisms alongside multimodal therapeutic approaches may reduce overall anxiety, thereby mitigating the experience of pain in the recovery from a burn wound. 


\section{STANDARDIZATION AND GUIDELINES}

Standardized pain and anxiety guidelines are used in many burn centers to ensure appropriate and consistent patient comfort. Ideally, pain management guidelines should ensure safety and efficacy over a broad range of burn severities while providing clear recommendations for drug selection, dosing, and titration. Frequent re-assessment of pain and anxiety levels can safeguard against inadequate treatment of pain in the burn unit. Bittner et al have proposed the following guidelines for sedation and analgesia in acute burns:

\begin{tabular}{|l|l|l|l|l|}
\hline Stage of Injury & Background Anxiety & Background Pain & Procedural Anxiety & Procedural Pain \\
\hline Acute Burn Ventilated & \#1 Midazolam infusion & Morphine infusion & Midazolam boluses & Morphine boluses \\
\hline & \#2 Dexmedetomidine infusion & Morphine infusion & $\begin{array}{l}\text { Dexmedetomidine } \\
\text { higher infusion rate }\end{array}$ & Morphine boluses \\
\hline & \#3 Antipsychotics & Morphine infusion & $\begin{array}{l}\text { Haloperidol (very } \\
\text { slow) boluses }\end{array}$ & Morphine boluses \\
\hline $\begin{array}{l}\text { Acute Burn not } \\
\text { ventilated }\end{array}$ & $\begin{array}{l}\text { \#4 Propofol infusion (<48 h) } \\
\text { Scheduled Lorazepam IV or } \\
\text { PO }\end{array}$ & $\begin{array}{l}\text { Morphine infusion } \\
\text { PO }\end{array}$ & Propofol boluses & Morphine boluses \\
\hline Chronic Acute Burn & $\begin{array}{l}\text { Scheduled lorazepam or } \\
\text { antipsychotics (PO) }\end{array}$ & $\begin{array}{l}\text { Scheduled } \\
\text { morphine or } \\
\text { methadone }\end{array}$ & $\begin{array}{l}\text { Lorazepam IV/PO } \\
\text { antipsychotics (PO) }\end{array}$ & $\begin{array}{l}\text { Morphine IV/PO } \\
\text { or Ketamine IV }\end{array}$ \\
\hline
\end{tabular}

Fentanyl infusions could be substituted for morphine infusions.

In view of the increased incidence of delirium with benzodiazepines, minimal use of them is advocated. $\mathrm{IV}=$ intravenous. $\mathrm{PO}=$ per oram $($ by mouth).

\section{CONCLUSION}

Though pain management is a major challenge for clinicians, good pain control is the foundation of efficacious burn care from initial injury to long term recovery. The very treatments designed to treat burn wounds may inflict more pain that the initial injury itself, making it the clinicians duty to embrace a multimodal treatment approach to burn pain. Vigilant pain assessment, meaningful understanding of the pathophysiology and pharmacological considerations across different phases of burn injury, and compassionate attention to anxiety and other psychosocial contributors to pain will enhance the clinician's ability to provide excellent pain management.

\section{Supplementary Material}

Refer to Web version on PubMed Central for supplementary material.

\section{Acknowledgments}

Disclosure statement: Dr B. Levi was supported by funding from National Institutes of Health/National Institute of General Medical Sciences grant K08GM109105-0, American Association of Plastic Surgery Academic Scholarship, and American College of Surgeons Clowes Award. Dr B. Levi collaborates on a project unrelated to this review with Boehringer Ingelheim. 


\section{References}

Patterson DR, et al. Pain Management. Burns. 2004; 30:A10-A15. [PubMed: 15555783]

Patterson DR, Carrigan K, Questad KA, Robinson R. Posttraumatic stress disorder in hospitalized patients with burn injuries. J Burn Care Rehabil. 1990; 11:181-4. [PubMed: 2373725]

Saxe GN, Stoddard F, Hall E, Chawla N, Lopez C, Sheridan R, King D, King L, Yehuda R. Pathways to PTSD, part 1: Children with burns. Am J Psychiatry. 2005; 162:1299-304. [PubMed: 15994712]

Raymond I, Ancoli-Israel S, Choiniere M. Sleep disturbances, pain and analgesia in adults hospitalized for burn injuries. Sleep Med. 2004; 5:551-9. [PubMed: 15511701]

Christian LM, Graham JE, Padgett DA, Glaser R, Kiecolt-Glaser JK. Stress and wound healing. Neuroimmunomodulation. 2006; 13:337-46. [PubMed: 17709956]

Faucher LD, Furukawa K. Practice guidelines for the management of pain. J Burn Care Rehabil. 2006; 27:659-68.

Meyer, WJ., III, Wiechman, SA., Woodson, L., Jaco, M., Thomas, CR. Chapter 64. Management of pain and other discomforts in burned patients. In: Herndon, DN., editor. Total Burn Care. 4. Saunders Elsevier; Philadelphia: 2012. p. 715

Choiniere M, Melzack R, Rondeau J, Paquin M. The pain of burns: characteristics and correlates. J Trauma. 1989; 29:1531-9. [PubMed: 2585565]

Brown NJ, Kimble RM, Gramotnev G, Rodger S, Cuttle L. Predictors of re-epithelialization in pediatric burn. Burns. 2014 Jun; 40(4):751-8. [PubMed: 24184285]

Tracey I. Imaging pain. BJA. 2008; 101:32-9. [PubMed: 18556697]

Patterson, DR., Sharar, SR. Burn pain. In: Fishman, SM.Ballantyne, JC., Rathmell, JP., editors. Bonica's Management of Pain. 4. Lippincott Williams and Wilkins; Philadelphia: 2010. p. 754

Wibbenmeyer L, Sevier A, Liao J, et al. Evaluation of the usefulness of two established pain assessment tools in a burn population. J Burn Care Res. 2011; 32:52. [PubMed: 21116190]

Williamson A, Hoggart B. Pain: a review of three commonly used pain rating scales. J Clin Nurs. 2005; 14:798-804. [PubMed: 16000093]

Cuthbertson DP. Postshock metabolic response. Lancet. 1942; 239:433-7.

Blancet B, Jullien V, Vinsonneau C, Tod M. Influence of burns on pharmacokinetics and pharmacodynamics of drugs used in the care of burn patients. Clin Pharmacokinet. 2008; 47:63554. [PubMed: 18783295]

Wang S, Zhang L, Ma Y, Chen L, Tian Y, Mao J, Martyn JJ. Nociceptive behavior following hindpaw burn injury in young rats: Response to systemic morphine. Pain Med. 2011; 12:87-98. [PubMed: 21143761]

Han T, Harmatz JS, Greenblatt DJ, Martyn JA. Fentanyl clearance and volume of distribution are increased in patients with major burns. J Clin Pharmacol. 2009; 47:674-80.

Kariya N, Shindoh M, Nishi S, Yukioka H, Asada A. Oral clonidine for sedation and analgesia in a burn patient. J Clin Anesth. 1998; 10:514-7. [PubMed: 9793819]

Williams PI, Sarginson RE, Ratcliffe JM. Use of methadone in the morphine-tolerant burned paediatric patient. Br J Anaesth. 1998; 80:92-5. [PubMed: 9505787]

Walker J, MacCallum M, Fischer C, Kopcha R, Saylors R, McCall J. Sedation using dexmedetomidine in pediatric burn patients. J Burn Care Res. 2006; 27:206-10. [PubMed: 16566567]

Lin H, Faraklas I, Sampson C, Saffle JR, Cochran A. Use of dexmedetomidine for sedation in critically ill mechanically ventilated pediatric burn patients. J Burn Care Res. 2001; 32:98-103.

Martyn JA, Richtsfeld M. Succinylcholine induced hyperkalemia in acquired pathologic states. Anesthesiology. 2006; 1004:158-69.

Gray P, Williams B, Cramon T. Sucessful Use of Gabapentin in Acute Pain Management Following Burn Injury: A Case Series. Pain Medicine. 2008; 9(3):371-376. [PubMed: 18366516]

Dirks J, Petersen KL, Rowbotham MC, Dahl JB. Gabapentin suppresses cutaneous hyperalgesia following heat-capsaicin sensitization. Anesthesiology. 2002; 97(1):102-7. [PubMed: 12131110]

Wibbenmeyer L, Eid A, Liao J, Heard J, Horsfield A, Kral L, Kealey P, Rosenquist R. Gabapentin is ineffective as an analgesic adjunct in the immediate postburn period. J Burn Care Res. 2014; 35(2): 136-42. [PubMed: 23511293] 
Lynn SJ. Hypnosis and the treatment of posttraumatic conditions: an evidence-based approach. Int J Clin Exp Hypn. 2007; 55(2):167-88. [PubMed: 17427292]

Hoffman HG, Patterson DR, Carrougher GJ. Use of virtual reality for adjunctive treatment of adult burn pain during physical therapy. Clin J Pain. 2000; 16(3):244-50. [PubMed: 11014398]

Hoffman HG, Patterson DR, Seibel E, Soltani M, Jewett-Leahy L, Sharar SR. Virtual reality pain control during burn wound debridement in the hydrotank. Clin J Pain. 2008; 24(4):299-304. [PubMed: 18427228] 


\section{KEY POINTS}

- $\quad$ Pain management in burn patients, while challenging, is critically important to optimum care of this population.

- Better outcomes in healing, anxiety and rehabilitation are linked to good pain control in burns.

- $\quad$ Pain assessment requires understanding of acute, chronic and procedural forms of burn related pain.

- Multimodal pharmacologic approaches, with opiods as the mainstay of pain control, are ideal for burn injured patients.

- $\quad$ Perioperative management demands understanding of complex physiology and dynamic pharmacokinetic changes that occur during the acute injury and resuscitation phase, especially in larger burns. 